\title{
Fast Prediction of Voltage Stability Index Based on Radial Basis Function Neural Network: Iraqi Super Grid Network, 400-kV
}

\author{
Omer H. Mehdi \& Noor Izzri \\ Department of Electrical and Electronic Engineering, Faculty of Engineering \\ University Putra Malaysia, 43400 UPM Serdang, Selangor, Malaysia
}

Mohammad K. Abd

Department of Electrical and Electronic Eng., University of Technology, Baghdad, Iraq

Received: May 15, 2011

Accepted: June 13, 2011

doi:10.5539/mas.v5n4p190

\begin{abstract}
With the increase in power demand and limited power sources has caused the system to operate at its maximum capacity. Therefore, the ability of determine voltage stability before voltage collapse has received a great attention due to the complexity of power system. In this paper a prediction of voltage stability index (VSI) based on radial basis function neural network (RBFNN) for the Iraqi Super Grid network, 400KV. Learning data has been obtained for various settings of load variables using load flow and conventional FVSI method. The input data was performed by using a 135 samples test with different bus voltage $\left(\mathrm{V}_{\mathrm{b}}\right)$, Bus active and reactive power $\left(\mathrm{P}_{\mathrm{b}}, \mathrm{Q}_{\mathrm{b}}\right)$, bus load angle $\left(\delta_{\mathrm{b}}\right)$ and $\mathrm{FVSI}_{\mathrm{ij}}$. The RBFNN model has four input representing the $\left(\mathrm{V}_{\mathrm{b}}, \mathrm{P}_{\mathrm{b}}, \mathrm{Q}_{\mathrm{b}}\right.$ and $\left.\delta_{\mathrm{b}}\right)$, sixteen nodes at hidden layer and one output node representing $\mathrm{FVSI}_{\mathrm{ij}}$ have been used to assess the security on line. The proposed method has been tested in the IEEE 30 and a practical system. In Simulation results show that the proposed method is more suitable for on-line voltage stability assessment in term of automatically detection of critical transmission line when additional real or reactive loads are added.
\end{abstract}

Keywords: Voltage stability index, Radial basis function neural network, Voltage collapse

\section{Introduction}

Recent year's voltage stability is considered as an important concern in to power system operation and planning since the heavily loaded systems are mostly operated closer to the reactive power limits of the transmission network (Suthar and Balasubramanian, 2007). The voltage problems are often associated with contingencies like unexpected line and generator outages, insufficient local reactive power supply and increased loading of transmission lines. However, stability assessment has been performed mainly off-line by system planners because the computational burden is too high for online stability assessment. Consequently, in tradition, system planners determine the stability limits of transmission corridors for operators to monitor system. System planners also developed operating guidelines to help operators to mitigate the problems.

Over the last few decades, a number of direct methods for assessment on-line transient stability have been identified and investigated. This gives more and higher requirements for new models and tools for voltage stability analysis (Zhao et al., 2009). The voltage instability can occur when a power system is heavily loaded in transmission lines and/or lacks in local reactive power sources (Joong, 2007). Although the voltage stability problem is in its nature a dynamic one, a great deal of the research work has been devoted to the static methods in real-time applications. ( Haque, 2003) used the results of power flow study and the system admittance matrix to find the parameters of the Thevenin's equivalent of the system, looking from various load buses. (Lee and Lee, 2002) introduced a criterion for static voltage stability enhancement and used accurate models for excitation systems, tap changer and other equipment for analysis of dynamic voltage stability. The voltage stability problem can be considered as a non-issue in distribution systems. However, in modern distribution systems, as they become more complex and large, the issue can be one of the critical problems. There have been some attempts to use ANN for online voltage stability assessment (Kamalasadan et al., 2006) and comes out with voltage stability margin at the system level. In addition, various other methods for voltage stability assessments of power systems have been documented using static and dynamic methods in small radial network was performed by (Hasani and Parniani, 2005). Some advantages of dynamic simulation of this phenomenon were shown by (Deuse and Stubbe, 1993). (Taylor, 1994 and Kundur, 1994) proposed different static methods and dynamic simulation with appropriate models for voltage stability assessments. However, methods based on the dynamic approach are exceptionally time consuming in terms of computer time for the online environment. An especially attractive means for solving the aforementioned problem is found in artificial neural networks (ANNs) (Fischl, 1996). Mohammad and Hadi (2008) attempts have been made to set up a direct mapping between the operating states of the system and the VSM index using supervised neural networks (NNs).

In this paper, a new intelligent application is developed to improve the voltage stability for Iraq super grid power systems. First, definitions and issues of voltage stability indices are presented. Secondly, the problem has been 
formulated as by a conventional approach based on the Fast voltage Stability Index (FVSI) and FVSI have been obtained for various line outages and for various reactive power control variables and loading conditions and using these results a RBFNN ANN is trained. Finally, the tests were carried out on the eastern part of the high-voltage power system of former Iraqi super grid $400 \mathrm{KV}$ to demonstrate its favorable performance by using MATLAB 10 neural network toolbox.

\section{Related Work}

A) Conversional Fast Voltage Stability Index

Fast voltage stability index (FVSI) is formulated in this study as the measuring instrument in predicting the voltage stability condition in the system. The proposed index made used the same concept as the existing ones (Moghavemmi and Omar, 1998 and Mohamed et al., 1989) in which discriminate is set to be greater or equal than/to zero to achieve stability. If the discriminate is small than zero, the roots for the voltage or could cause instability in the system. The mathematical formulation is very simple that could speed up the computation. The condition of voltage stability in a power system can be characterized by the use of voltage stability index referred to line. Generally, it started with the current equation to form the power or voltage quadratic equations. The criterion employed in this paper was to set the discriminate of the roots of voltage or power quadratic equation to be greater than zero. When the discriminate is less than zero, it causes the roots of the quadratic equations to be imaginary which in turn causing the voltage instability that may cause voltage collapse in the system. The line index that is evaluated close to 1.00 will indicate the limit of voltage instability.

Fig.3. illustrates a 2-bus power system model where the proposed FVSI is derived from the symbols are explained as follows:

$\mathrm{V}_{\mathrm{i}}, \mathrm{V}_{\mathrm{j}}=$ Voltage on sending and receiving buses

$\mathrm{P}_{\mathrm{i}}, \mathrm{Q}_{\mathrm{i}}=$ Active and reactive power on the sending bus

$\mathrm{P}_{\mathrm{j}}, \mathrm{Q}_{\mathrm{j}}=$ Active and reactive power on the receiving bus

$\mathrm{S}_{\mathrm{i}}, \mathrm{S}_{\mathrm{j}}=$ Apparent power on the sending and receiving buses

$\delta_{\mathrm{ij}}=\delta_{\mathrm{i}}-\delta_{\mathrm{j}}$

$=$ Angle difference between sending and receiving buses

The line impedance is noted as $\mathrm{Z}_{\mathrm{ii}}=\mathrm{R}_{\mathrm{ii}}+\mathrm{j} \mathrm{X}_{\mathrm{ij}}$ with the current that flows in the line IS given by

$I=\frac{v_{i}<\hat{\theta}_{i}-v_{j}<\hat{\theta}_{j}}{R_{i j}+j x_{i j}}$

$V_{i}$ is taken as the reference, and therefore the angle is shiftedinto 0 . The apparent power at bus 2 can be written as; $\mathrm{S}_{\mathrm{j}}=\mathrm{V}_{\mathrm{i}} \mathrm{I}^{*}$

Rearranging (2) yields;

$\mathrm{I}=\left(\frac{s_{j}}{\mathrm{~V}_{\mathrm{j}}}\right) *$

$I=\frac{P_{j}-j Q_{j}}{v_{j}<s_{j}}$

Equating (1) and (4) we obtained,

$\frac{V_{i}<\hat{\theta}_{i}-V_{j}<\hat{\delta}_{j}}{R_{i j}+j x_{i j}}=\frac{P_{j}-j Q_{j}}{V_{j} \angle \sigma_{j}}$

$\mathrm{V}_{\mathrm{i}} \mathrm{V}_{\mathrm{j}} \angle \delta_{\mathrm{i}}-\delta_{\mathrm{j}}-\mathrm{V}_{\mathrm{j}}^{2} \angle \delta_{\mathrm{j}}=\left(\mathrm{R}_{\mathrm{ij}}+\mathrm{j} \mathrm{X}_{\mathrm{ij}}\right)\left(\mathrm{P}_{\mathrm{j}}-\mathrm{j} \mathrm{Q}_{\mathrm{j}}\right)$

Separating the real and imaginary parts yields,

$\mathrm{V}_{\mathrm{i}} \mathrm{V}_{\mathrm{j}} \cos \delta_{\mathrm{ij}}-\mathrm{V}_{\mathrm{j}}^{2}=\mathrm{R}_{\mathrm{ij}} \mathrm{P}_{\mathrm{j}}+\mathrm{X}_{\mathrm{ij}} \mathrm{Q}_{\mathrm{j}}$

And,

$-\mathrm{V}_{\mathrm{i}} \mathrm{V}_{\mathrm{j}} \sin \delta_{\mathrm{ij}}=\mathrm{X}_{\mathrm{ij}} \mathrm{P}_{\mathrm{j}}-\mathrm{R}_{\mathrm{ij}} \mathrm{Q}_{\mathrm{j}}$

Rearranging (7) for $\mathbf{P}_{\mathbf{j}}$ and substituting into (6) yields a quadratic equation of $\mathrm{V}_{\mathrm{j}}$;

The roots for $\mathrm{V}_{\mathrm{i}}$ will be;

$\mathrm{V}_{\mathrm{j}}^{2}-\left(\frac{\mathrm{B}_{\mathrm{ij}}}{\mathrm{X}_{\mathrm{ij}}} \sin \delta_{\mathrm{ij}}+\cos \delta_{\mathrm{ij}}\right) \mathrm{V}_{\mathrm{i}} \mathrm{V}_{\mathrm{j}}+\left(\mathrm{X}_{\mathrm{ij}}+\frac{R_{i j}^{2}}{X_{i j}}\right) \mathrm{Q}_{\mathrm{j}}=0$

$V_{j}=\frac{\left[\frac{R_{i j}}{x_{i j}} \sin s_{i j}+\cos s_{i j}\right] V_{i} \pm \sqrt{\left[\left(\frac{R_{i j}}{x_{i j}} \sin s_{i j}+\cos s_{i j}\right) V_{i}\right]^{2}-4\left(X_{i j}+\frac{R_{i j}^{2}}{x_{i j}}\right) Q_{j}}}{2}$

To obtain real roots for $\mathbf{V}_{\mathbf{j}}$, the discriminate is set greater than or equal to ' 0 '; i.e.: 


$$
\begin{aligned}
& {\left[\left(\frac{R_{\mathrm{ij}}}{\mathrm{X}_{\mathrm{ij}}} \sin \delta_{\mathrm{ij}}+\cos \delta_{\mathrm{ij}}\right) \mathrm{V}_{\mathrm{i}}\right]^{2}-4\left(\mathrm{X}_{\mathrm{ij}}+\frac{\mathrm{R}_{\mathrm{ij}}^{2}}{x_{i j}}\right) \mathrm{Q}_{\mathrm{j}} \geq 0} \\
& \frac{4 z_{i j}^{2} Q_{j} X_{i j}}{\left(\mathrm{~V}_{\mathrm{i}}\right)^{2}\left(\mathrm{R}_{\mathrm{ij}} \sin \delta_{\mathrm{ij}}+\mathrm{X}_{\mathrm{ij}} \cos \delta_{\mathrm{ij}}\right)^{2}} \leq 1
\end{aligned}
$$

Since $\delta_{\mathrm{ij}}$ is normally very small then,

$\delta_{\mathrm{ij}} \approx 0, \mathrm{R}_{\mathrm{ij}} \sin \delta_{\mathrm{ij}} \approx 0$, and $\mathrm{X}_{\mathrm{ij}} \cos S_{i \mathrm{i}} \approx \mathrm{X}_{\mathrm{ij}}$

Taking the symbols ' $\mathrm{i}$ ' as the sending bus and ' $\mathrm{j}$ ' as the receiving bus. Hence, the fast voltage stability index, FVSI can be defined by:

$$
\mathrm{FVSI}_{\mathrm{ij}}=\frac{4 Z_{i j}^{2} Q_{j}}{V_{i}^{2} X_{i j}}
$$

Where: $\quad \mathbf{Z}_{\mathrm{ij}}=$ line impedance

$\mathrm{X}_{\mathrm{ij}}=$ line reactance

$\mathrm{Qj}=$ reactive power at the receiving end

$\mathrm{Vi}=$ sending end voltage

The value of FVSI that is evaluated close to 1.00 indicates that the particular line is closed to its instability point which may lead to voltage collapse in the entire system. To maintain a secure condition the value of FVSl should be maintained well less than 1.00.

\section{B) Radial Basis Function Neural Network}

RBFNN have increasingly attracted interest for engineering applications due to their advantages over traditional multilayer perceptions, namely faster convergence, smaller extrapolation errors, and higher reliability. Over the last few years, more sophisticated types of neurons and activation functions have been introduced in order to solve different sorts of practical problems (Kumar, 2005; Kurban and Beşdok, 2009). In particularly, RBFNN have proved very useful for many systems and applications (Kumar, 2005). RBFNN is defined as a kind of ANN that has radial activation functions on its intermediary layer. RBFNN were robust used in the context of neural networks as linear and nonlinear function estimators and indicated their interpolation capabilities by Broomhead and Lowe (Broomhead and Lowe, 1988). (Hartman et al., 1990; Park and Sandberg, 1993) proved that RBFNN are capable of approximating any function with arbitrary accuracy. The neural network is a mapping between its inputs and outputs based on a number of known sample input-output pairs. In general, the more samples available to train the network, the more accurate the representation of the real mapping will be. These samples are obtained by solving the direct problem (times), in its simplest form, a RBFNN consists of three layers of neurons, Fig.1. The first layer acts as the input layer of the ANN. The second layer is hidden layer as a high-scale dimension, which promotes a linear transformation of input space dimension by computing radial functions in their neurons. Third layer, the output layer, outputs the ANN response, promoting a linear transformation of the intermediary layer high-scale dimension to the low-scale dimension (Pandya , 1995).

\section{Material and Method}

\section{A) RBFNN Model for FVSI}

Several types of ANN structures and training algorithms have been proposed. The basic form of RBFNN architecture involves entirely three different layers. The input layers is made $\mathrm{n}$, of source nodes while the second layer is hidden layer of high enough dimension which senses a different purpose from that in a multilayer perception.

The output layer supplies the response of the network to the activation patterns applied to the input layer. The transformation from the input layer to the hidden layer is nonlinear whereas the transformation from the hidden layer to the output layer is linear.

From above analytical methods involve considerable computational effort and hence cannot be used directly for online monitoring and initiation of preventive control actions to enhance system voltage stability. The major steps of the RBFNN design and training to determining the voltage instability problem are summarized by the following steps:

a. A set of realistic system loading patterns a regenerated by varying the real power and reactive power loadings at various line outages and for various reactive power control variables and loading conditions.

b. For each of the loading patterns generated in step (a) the load flow and modal analysis of the reduced Jacobian matrix are done and FVSI was calculated for each line in the system to identify the most vulnerable few load buses from the voltage stability point of view.

c. The RBFNN is designed and trained by the input patterns $\left(\mathrm{V}_{\mathrm{b}}, \delta_{\mathrm{b}}, \mathrm{P}_{\mathrm{b}}, \mathrm{Q}_{\mathrm{b}}\right)$ for each bus is generated as shown in Fig.4. 
d. The RBFNN, the target output is FVSI to show distance to voltage collapse for each input pattern is computed by running the contour program.

e. Finally, training of these RBFNN using the input/output patterns developed in Steps 3 and 4 is carried out.

B) Iraqi super grid network

The transmission level in the Iraqi electrical network consists of the $400 \mathrm{KV}$ network (the super grid network) and part of the $132 \mathrm{kV}$ network connected to it. The aim of this work is limited to the study of only the $400 \mathrm{KV}$ network with all its bus-bars and transmission lines.

The network under consideration consists of 24 bus bars and 30 transmission lines (the total transmission line $3664.6 \mathrm{Km}$ ) and configuration of this network shown in Fig.2.

\section{Results and Discussion}

To demonstrate the effectiveness of the proposed technique for online voltage stability monitoring for different types of contingencies including variable load and line outage has been applied to the Iraqi super grid network 24-bus test system. For generating training data for the RBFNN, active and reactive power set the load buses are varied within $5,10,15,20$, and $25 \%$ of the base case values. For each operating condition, bus operating parameter selected transmission lines are recorded as the input features. Contingency analysis is performed for all line outages and the MW margins to voltage instability are recorded by using Matlab 10 and table $(1,2)$ shows the bus data and transmission line data. A flow chart describing the modal analysis procedure adopted is presented in Fig.5. The experiment results were used to train the neural network which have been constructed and trained using 135 data samples from the experimental data and 16 samples were used for generalization test of the trained neural network.

From the analysis of the results in Table 3 show the FVSI for five load change. As mentioned above that system will unstable when FSVI near to 1 therefore it is clear that the system is unstably with increasing the load change and increasing of FSVI depend on the bus type for example the Transmission line connect to Gen. Bus or Reference bus are more stable because they near to source. In addition, for a given operating condition, the most critical transmission line in the system has been identified and appropriate algorithms i.e. $\mathrm{TL}_{6-15}$ is unstable under $25 \%$ load change.

From the analysis of the results in Table 4, it is observed that the accuracy of the RBFNN method was slightly superior when compared to the CFVSI on account of both maximum error and mean average error (MAE) for both load change.

\section{Conclusion}

In this study voltage stability assessment of power systems by using RBFNN has been explored, and this was obvious from the generalization test. The simulation data from FVSI test has been used for training and testing. Using this approach, for a given operating condition, the most critical transmission line of the system has been identified and appropriate algorithms, which directly employ the designed NN architecture, have been suggested to evaluate on-line the previously considered control strategies. The difference of FVSI between prediction by RBFNN and CFSVI test is considered almost negligible; this means that it can solve many problems that have been costly and time consuming. The effectiveness of the proposed approach has been tested on Iraqi super grid power system.

\section{References}

Suthar, B. and Balasubramanian, R. (2007). Application of an ANN based voltage stability assessment tool to restructured power systems. Bulk Power System Dynamics and Control - VII. Revitalizing Operational Reliability, 2007 iREP Symposium, IEEE. (19-24): 1

Zhao, J.; Wang, Y. and Xu, P. (2009). A Comprehensive on-line voltage stability assessment method based on continuation power flow. Sustainable Power Generation and Supply International Conference, IEEE. (6-7): 1 - 5 Kamalasadan, S., Srivastava, A. K., Tukaram, D. (2006). Novel Algorithm for Online Voltage Stability Assessment Based on Feed Forward Neural Network. presented at 2006 PES general meeting Montreal, Canada. Mohammad, V. and Hadi, R. (2008). Dynamic voltage stability assessment of power transmission systems using neural networks. Energy Conversion and Management. 49 (6): 1-7.

Joong, R. S., Byung S. K., Jong B. P. and Lee, K.Y. (2007). A new optimal routing algorithm for loss minimization and voltage stability improvement in radial power systems. Power Systems, IEEE Transactions on. 22 (2): 648

Hasani, M. and Parniani, M. (2005). Method of combined static and dynamic analysis of voltage collapse in voltage stability assessment. Transmission and Distribution Conference and Exhibition: Asia and Pacific, IEEE/PES. (2005): 1.

Haque, M.H. (2003). Novel method of assessing voltage stability of a power system using stability boundary in P-Q plane. Electric Power System Research. 64(1):35-40. 
Deuse, J. and Stubbe, M. (1993). Dynamic simulation of voltage collapses. IEEE Trans. on Power Systems. 8: 894-900.

Lee, B.H. and Lee, K.Y. (2002). Dynamic and static voltage stability enhancement of power systems. IEEE Trans. on Power Systems. 8: .231-238.

Taylor C.W. (1994). Power system voltage stability. New York: McGraw-Hill.

Kundur, P. (1994). Power System Stability and Control. New York: McGraw-Hill.

Fischl, R., Neibur, D. and El-Sharkawi, M. A. (1996). Security assessment and enhancement, in IEEE Tutorial Course 'Artificial neural networks with applications to power systems'. New York. IEEE. 104-127

Moghavemmi, M. and Omar, F. M. (1998). Technique for Contingency Monitoring and Voltage Collapse Prediction. IEEE Proceeding on Generation, Transmission and Distribution. 145(634 - 640):6.

Mohamed, A., Jasmon, G. B. and Yusoff, S. (1989). A Static Voltage Collapse Indicator Using Line Stability Factors. Journal of Industrial Technology. 7(1):73-85.

Broomhead, D.S. and Lowe, D. (1988). Multivariable function interpolation and adaptive networks. Complex System. 2:321-355.

Kumar, S. (2005). Neural Networks: A Class room Approach. ISBN 007-124672-X

Kurban, T. and Beşdok, E. (2009). A Comparison of RBF Neural Network Training Algorithms for Inertial Sensor Based Terrain Classification. Sensors. 9: 6312-6329.

Hartman, E. J., Keeler, J. D. and Kowalski, J. M. (1990). Layered neural networks with Gaussian hidden units as universal approximators. Neural Computing journal. 2:210-215

Park, J. and Sandberg, I.W. (1993). Universal approximation and radial basis-function networks. Neural Computing journal. 5: 305-316.

Pandya , A.S. (1995). in: pattern recognition with neural networks in $\mathrm{C}++$.

Table 1. Bus data for Iraq Super Grid

\begin{tabular}{|c|c|c|c|c|c|c|c|}
\hline $\begin{array}{c}\text { Bus } \\
\text { No. }\end{array}$ & $\begin{array}{c}\text { Bus } \\
\text { Code }\end{array}$ & $\begin{array}{c}\text { Bus } \\
\text { Voltage }\end{array}$ & $\begin{array}{c}\text { Bus } \\
\text { Angle }\end{array}$ & $\begin{array}{c}\text { Load } \\
\text { MW }\end{array}$ & $\begin{array}{c}\text { Load } \\
\text { Mvar }\end{array}$ & $\begin{array}{c}\text { Gen } \\
\text { MW }\end{array}$ & $\begin{array}{c}\text { Gen } \\
\text { Mvar }\end{array}$ \\
\hline 1 & 1 & 1.025 & 0 & 0 & 0 & 0 & 0 \\
\hline 2 & 2 & 1 & -6.422 & 0 & 0 & 998 & 0 \\
\hline 3 & 0 & 0.9872 & -36.681 & 776.24 & 274.967 & 0 & 0 \\
\hline 4 & 2 & 0.99 & -36.664 & 0 & 0 & 956 & 0 \\
\hline 5 & 2 & 1 & -43.189 & 173.326 & 61.1221 & 260 & 0 \\
\hline 6 & 0 & 0.951 & -57.640 & 672.525 & 284.514 & 0 & 0 \\
\hline 7 & 0 & 0.980 & -61.037 & 0 & 0 & 0 & 0 \\
\hline 8 & 0 & 0.972 & -61.892 & 963.482 & 349.459 & 0 & 0 \\
\hline 9 & 0 & 0.982 & -61.661 & 533.953 & 184.268 & 0 & 0 \\
\hline 10 & 2 & 0.99 & -61.705 & 0 & 0 & 0 & 0 \\
\hline 11 & 0 & 0.976 & -61.567 & 124.763 & 53.8677 & 0 & 0 \\
\hline 12 & 0 & 0.956 & -59.090 & 64.2869 & 173.375 & 0 & 0 \\
\hline 13 & 0 & 0.972 & -60.382 & 105.411 & 20.2787 & 0 & 0 \\
\hline 14 & 0 & 0.934 & -88.740 & 340.817 & 109.199 & 0 & 0 \\
\hline 15 & 2 & 1 & -49.758 & 254.445 & 72.1922 & 0 & 0 \\
\hline 16 & 0 & 0.994 & -51.535 & 129.545 & 41.4657 & 0 & 0 \\
\hline 17 & 2 & 1 & -60.064 & 214.376 & 68.0632 & 1200 & 0 \\
\hline 18 & 2 & 1 & -59.904 & 0 & 0 & 500 & 0 \\
\hline 19 & 0 & 0.991 & -62.103 & 401.600 & 77.3193 & 0 & 0 \\
\hline 20 & 0 & 0.976 & -65.806 & 264.633 & 183.590 & 0 & 0 \\
\hline 21 & 2 & 1 & -79.779 & 457.697 & 221.117 & 840 & 0 \\
\hline 22 & 0 & 0.957 & -94.941 & 319.107 & 168.702 & 0 & 0 \\
\hline 23 & 2 & 0.99 & -94.286 & 177.971 & 88.0291 & 400 & 0 \\
\hline 24 & 2 & 1 & -94.710 & 742.511 & 262.080 & 0 & 0 \\
\hline
\end{tabular}


Table 2. Transmission Line for Iraqi Super Grid

\begin{tabular}{|c|c|c|c|}
\hline $\mathrm{Bn} 1$ & $\mathrm{Bnr}$ & Rline & Xline \\
\hline 1 & 2 & 0.00072 & 0.005885 \\
\hline 2 & 3 & 0.0021 & 0.017185 \\
\hline 3 & 4 & $2.00 \mathrm{E}-05$ & 0.0002 \\
\hline 3 & 6 & 0.002415 & 0.021965 \\
\hline 3 & 15 & 0.00345 & 0.03132 \\
\hline 4 & 5 & 0.0018 & 0.01635 \\
\hline 5 & 13 & 0.004247 & 0.038612 \\
\hline 6 & 9 & 0.00093 & 0.00847 \\
\hline 6 & 12 & 0.000616 & 0.005608 \\
\hline 6 & 15 & 0.00485 & 0.04405 \\
\hline 7 & 11 & 0.000215 & 0.00197 \\
\hline 7 & 12 & 0.000964 & 0.008772 \\
\hline 7 & 17 & 0.00122 & 0.01015 \\
\hline 7 & 18 & 0.001094 & 0.009106 \\
\hline 7 & 20 & 0.00308 & 0.02795 \\
\hline 8 & 9 & 0.00029 & 0.00262 \\
\hline 8 & 11 & 0.00041 & 0.003745 \\
\hline 8 & 13 & 0.000435 & 0.00394 \\
\hline 9 & 10 & $7.50 \mathrm{E}-05$ & 0.00069 \\
\hline 11 & 14 & 0.02744 & 0.22904 \\
\hline 14 & 21 & 0.00432 & 0.03928 \\
\hline 14 & 22 & 0.00479 & 0.04354 \\
\hline 15 & 16 & 0.00292 & 0.02391 \\
\hline 17 & 18 & 0.000125 & 0.001043 \\
\hline 17 & 19 & 0.000405 & 0.003365 \\
\hline 19 & 20 & 0.001165 & 0.009675 \\
\hline 20 & 21 & 0.00383 & 0.03485 \\
\hline 21 & 24 & 0.00439 & 0.03993 \\
\hline 22 & 23 & 0.00145 & 0.0132 \\
\hline 23 & 24 & 0.00059 & 0.00538 \\
\hline
\end{tabular}


Table 3. FVSI for five steps load change

\begin{tabular}{|c|c|c|c|c|c|}
\hline $\begin{array}{c}\text { Load } \\
\text { Change }\end{array}$ & $5 \%$ load & $\begin{array}{l}10 \% \\
\text { load }\end{array}$ & $\begin{array}{l}15 \% \\
\text { load } \\
\end{array}$ & $\begin{array}{l}20 \% \\
\text { load } \\
\end{array}$ & $\begin{array}{l}25 \% \\
\text { load } \\
\end{array}$ \\
\hline 1 & -0.02928 & 0.029523 & 0.05396 & 0.054856 & 0.056353 \\
\hline 2 & -0.26344 & -0.27432 & -0.291 & -0.31469 & -0.34741 \\
\hline 3 & 0.006403 & 0.007643 & 0.010081 & 0.014095 & 0.020486 \\
\hline 4 & -0.48051 & -0.50529 & -0.53133 & -0.55882 & -0.58809 \\
\hline 5 & 0.147592 & 0.26318 & 0.392607 & 0.53882 & 0.706606 \\
\hline 6 & 0.085468 & 0.166893 & 0.256578 & 0.355925 & 0.467017 \\
\hline 7 & -0.03611 & -0.03783 & -0.03955 & -0.04127 & -0.04299 \\
\hline 8 & -0.05673 & -0.06099 & -0.06559 & -0.07058 & -0.07607 \\
\hline 9 & -0.04877 & -0.05244 & -0.05639 & -0.06068 & -0.06541 \\
\hline 10 & 0.221753 & 0.397349 & 0.596469 & 0.825077 & 1.092725 \\
\hline 11 & -0.00503 & -0.00533 & -0.00565 & -0.00597 & -0.00631 \\
\hline 12 & -0.07227 & -0.0766 & -0.08108 & -0.08573 & -0.0906 \\
\hline 13 & 0.097303 & 0.141227 & 0.189549 & 0.243011 & 0.303139 \\
\hline 14 & 0.047124 & 0.071517 & 0.098034 & 0.127058 & 0.159348 \\
\hline 15 & -0.25074 & -0.26294 & -0.27559 & -0.28876 & -0.30258 \\
\hline 16 & -0.01686 & -0.018 & -0.0192 & -0.02046 & -0.02178 \\
\hline 17 & -0.0097 & -0.01036 & -0.01105 & -0.01178 & -0.01254 \\
\hline 18 & -0.00387 & -0.00414 & -0.00441 & -0.0047 & -0.005 \\
\hline 19 & 0.024478 & 0.025135 & 0.026291 & 0.028054 & 0.030616 \\
\hline 20 & -2.11093 & -2.19694 & -2.28684 & -2.3812 & -2.48112 \\
\hline 21 & 0.24773 & 0.360203 & 0.488359 & 0.634559 & 0.834146 \\
\hline 22 & -0.63028 & -0.65967 & -0.69051 & -0.72298 & -0.76485 \\
\hline 23 & -0.04077 & -0.04271 & -0.04465 & -0.04659 & -0.04853 \\
\hline 24 & 0.005207 & 0.007812 & 0.010576 & 0.013527 & 0.016722 \\
\hline 25 & -0.01176 & -0.01232 & -0.01288 & -0.01344 & -0.014 \\
\hline 26 & -0.08505 & -0.08839 & -0.09178 & -0.09521 & -0.09871 \\
\hline 27 & 0.200307 & 0.289762 & 0.390785 & 0.505018 & 0.653784 \\
\hline 28 & 0.363884 & 0.384151 & 0.405753 & 0.428776 & 0.754945 \\
\hline 29 & -0.02122 & -0.00687 & 0.008332 & 0.024468 & -0.07312 \\
\hline 30 & 0.050021 & 0.052807 & 0.055776 & 0.058941 & 0.105906 \\
\hline $\begin{array}{l}\text { Max. } \\
\text { FVSI }\end{array}$ & 0.363884 & 0.397349 & 0.596469 & 0.825077 & 1.092725 \\
\hline
\end{tabular}


Table 4. Comparison between CFVSI and RBFNN for 5, 25\% load change

\begin{tabular}{|c|c|c|c|c|c|c|}
\hline \multirow{2}{*}{$\begin{array}{l}\text { Load } \\
\text { Change }\end{array}$} & \multicolumn{2}{|c|}{ Conventional FVSI } & \multicolumn{2}{|c|}{ RBFNN-FSVI } & \multicolumn{2}{|c|}{ Error } \\
\hline & $\begin{array}{c}5 \% \\
\text { Load }\end{array}$ & $\begin{array}{l}25 \% \\
\text { load }\end{array}$ & $5 \%$ load & $\begin{array}{l}25 \% \\
\text { load }\end{array}$ & Error 5\% & $\begin{array}{l}\text { Error } \\
25 \%\end{array}$ \\
\hline 1 & -0.02928 & 0.056353 & -0.02455 & 0.06196 & 0.047241 & 0.056073 \\
\hline 2 & -0.26344 & -0.34741 & -0.26045 & -0.34659 & 0.029812 & 0.008164 \\
\hline 3 & 0.006403 & 0.020486 & 0.012300 & 0.02305 & 0.058969 & 0.02564 \\
\hline 4 & -0.48051 & -0.58809 & -0.47611 & -0.57854 & 0.043949 & 0.095552 \\
\hline 5 & 0.147592 & 0.706606 & 0.14810 & 0.714054 & 0.005163 & 0.074476 \\
\hline 6 & 0.085468 & 0.467017 & 0.08567 & 0.47178 & 0.002033 & 0.047627 \\
\hline 7 & -0.03611 & -0.04299 & -0.03458 & -0.04008 & 0.015268 & 0.029092 \\
\hline 8 & -0.05673 & -0.07607 & -0.04834 & -0.07079 & 0.083786 & 0.052825 \\
\hline 9 & -0.04877 & -0.06541 & -0.04508 & -0.05959 & 0.036912 & 0.058202 \\
\hline 10 & 0.221753 & 1.092725 & 0.22698 & 1.094931 & 0.052284 & 0.022061 \\
\hline 11 & -0.00503 & -0.00631 & 0.00144 & 0.000586 & 0.064787 & 0.068951 \\
\hline 12 & -0.07227 & -0.0906 & -0.07183 & -0.08733 & 0.004274 & 0.032619 \\
\hline 13 & 0.097303 & 0.303139 & 0.10248 & 0.307986 & 0.051774 & 0.048462 \\
\hline 14 & 0.047124 & 0.159348 & 0.04795 & 0.166177 & 0.008305 & 0.068299 \\
\hline 15 & -0.25074 & -0.30258 & -0.24672 & -0.29906 & 0.040145 & 0.035181 \\
\hline 16 & -0.01686 & -0.02178 & -0.00884 & -0.01788 & 0.08011 & 0.039044 \\
\hline 17 & -0.0097 & -0.01254 & -0.00203 & -0.00537 & 0.076634 & 0.071709 \\
\hline 18 & -0.00387 & -0.005 & 0.002518 & -0.00135 & 0.063913 & 0.036528 \\
\hline 19 & 0.024478 & 0.030616 & 0.03245 & 0.039859 & 0.079811 & 0.092438 \\
\hline 20 & -2.11093 & -2.48112 & -2.10326 & -2.48029 & 0.076653 & 0.008266 \\
\hline 21 & 0.24773 & 0.834146 & 0.25051 & 0.842448 & 0.027813 & 0.083025 \\
\hline 22 & -0.63028 & -0.76485 & -0.62799 & -0.76041 & 0.022801 & 0.044388 \\
\hline 23 & -0.04077 & -0.04853 & -0.03977 & -0.04169 & 0.009908 & 0.068407 \\
\hline 24 & 0.005207 & 0.016722 & 0.00791 & 0.018799 & 0.027112 & 0.020777 \\
\hline 25 & -0.01176 & -0.014 & -0.01043 & -0.01393 & 0.01326 & 0.000631 \\
\hline 26 & -0.08505 & -0.09871 & -0.07843 & -0.08891 & 0.06612 & 0.097965 \\
\hline 27 & 0.200307 & 0.653784 & 0.21012 & 0.662961 & 0.098187 & 0.091776 \\
\hline 28 & 0.363884 & 0.754945 & 0.37157 & 0.758552 & 0.076918 & 0.036073 \\
\hline 29 & -0.02122 & -0.07312 & -0.01831 & -0.06618 & 0.029043 & 0.069436 \\
\hline \multirow[t]{3}{*}{30} & 0.050021 & 0.105906 & 0.05470 & 0.107131 & 0.046892 & 0.012251 \\
\hline & & & \multicolumn{2}{|c|}{ Max. Error } & 0.044663 & 0.049865 \\
\hline & & & \multicolumn{2}{|c|}{ MAE } & 0.098187 & 0.097965 \\
\hline
\end{tabular}




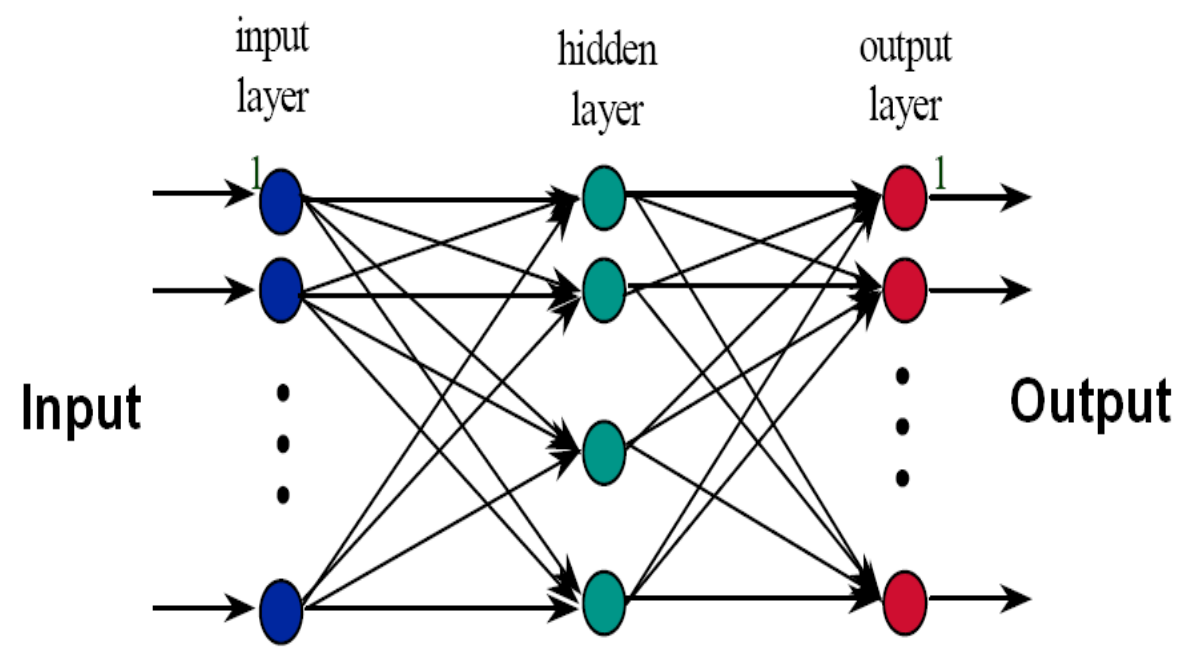

Figure 1. Radial Basis Function Neural Networks

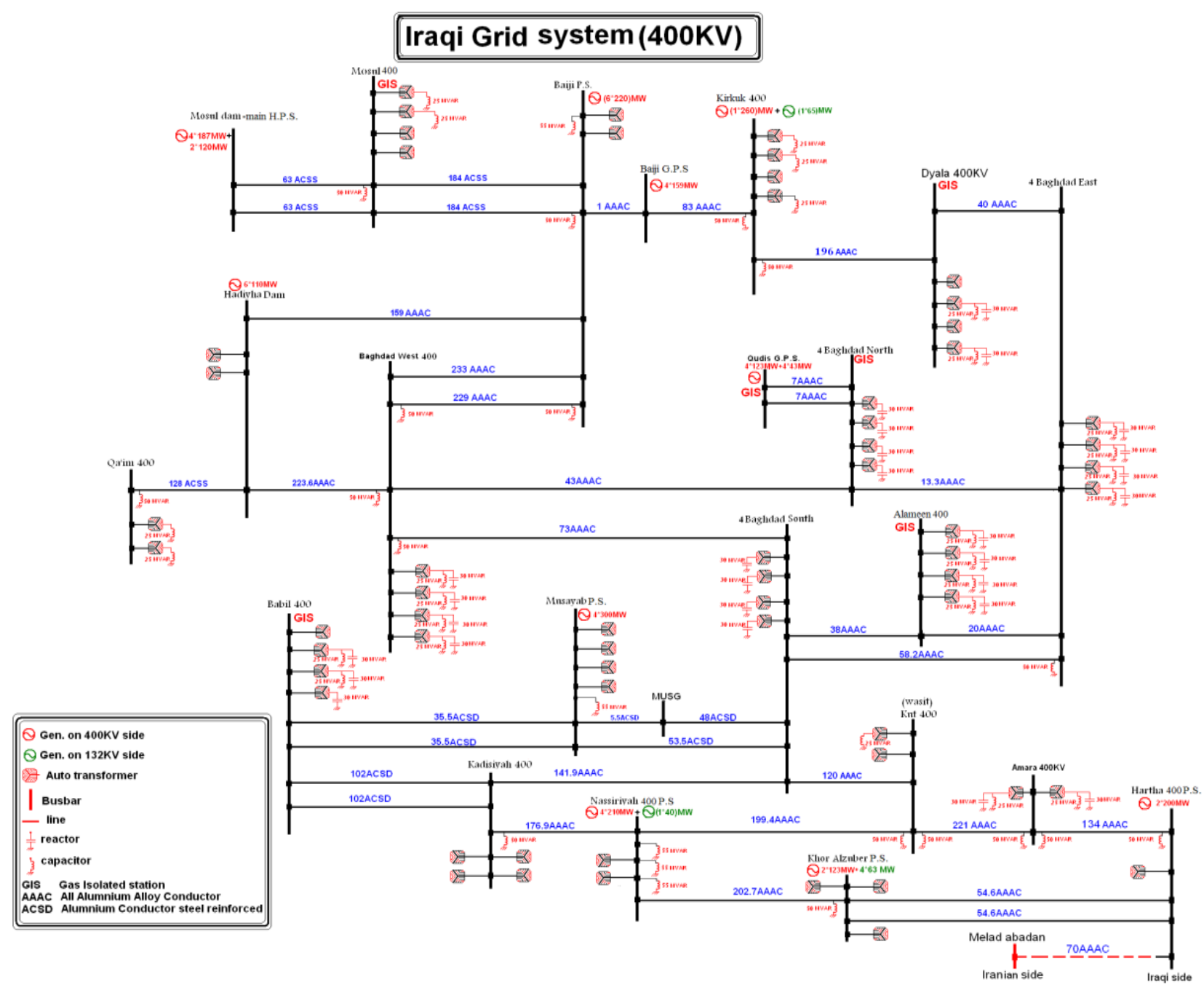

Figure 2. Iraqi super Grid network, $400 \mathrm{KV}$ 


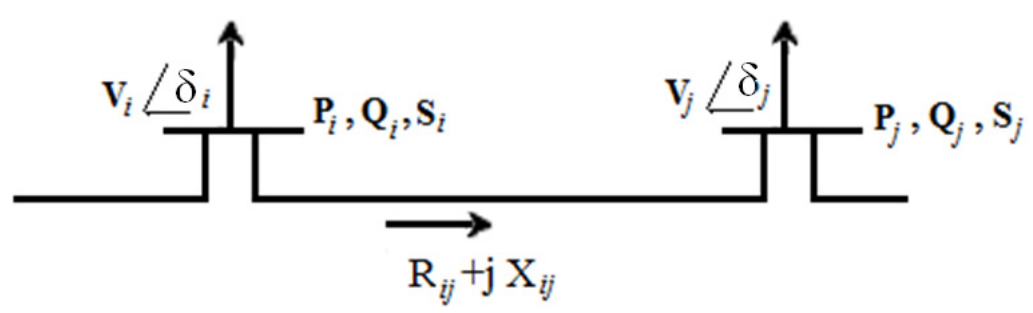

Figure 3. General Bus Power System Model

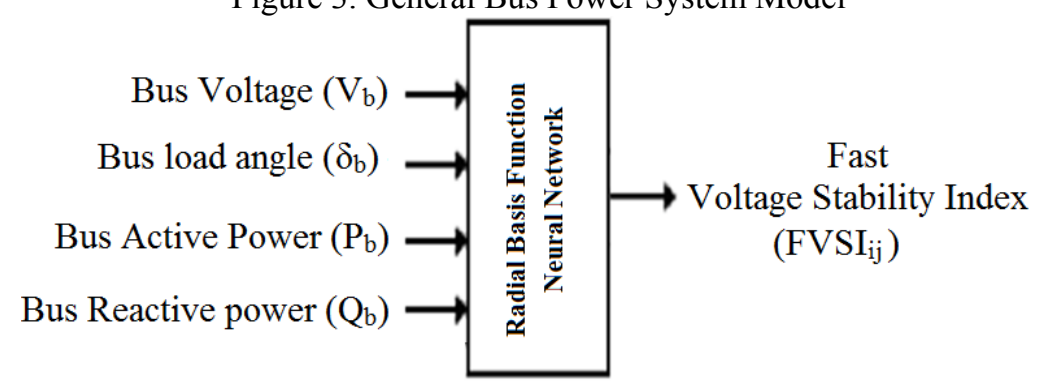

Figure 4. RBFNN FVSI Predication model

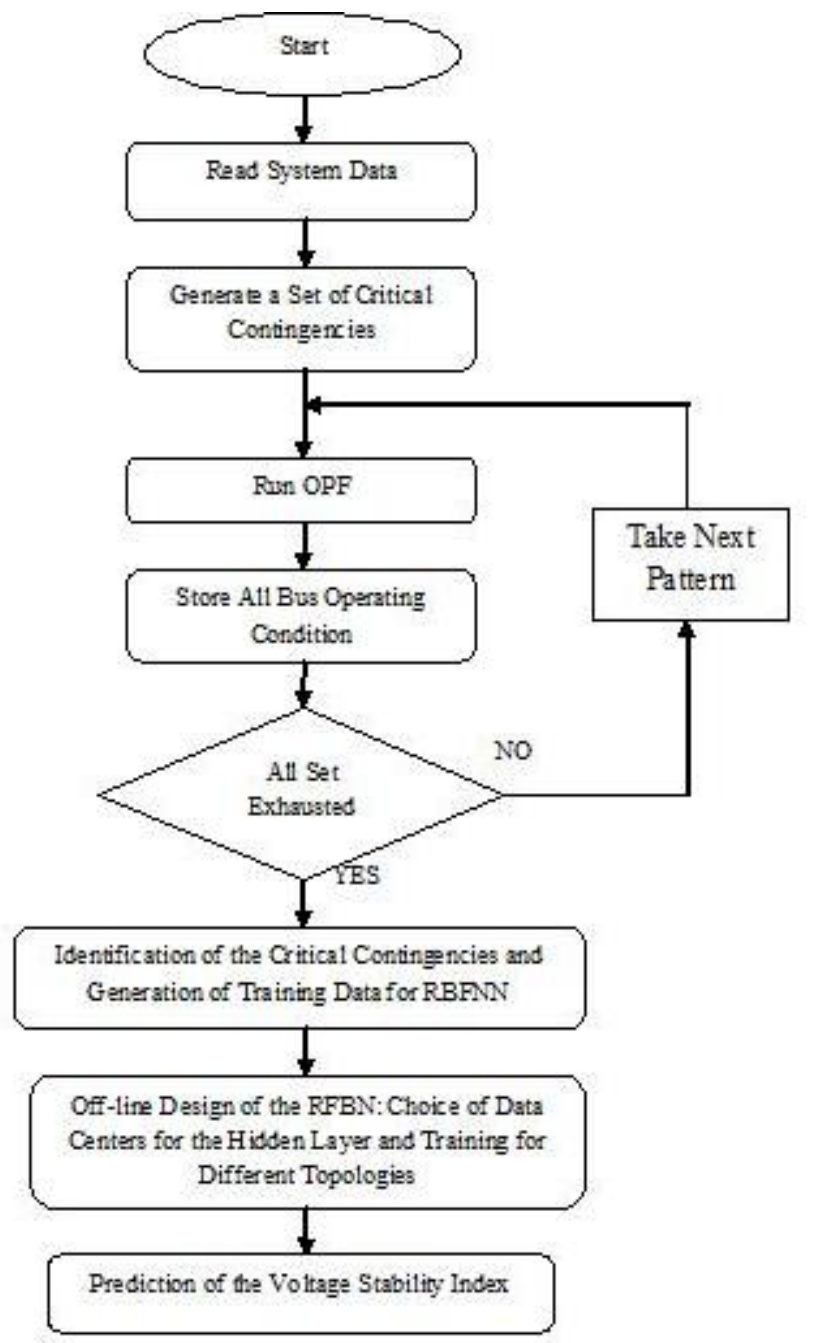

Figure 5. Online voltage stability monitoring algorithm 